Forum 2016 $\cdot 31: 518$

DOI 10.1007/s12312-016-0173-y

Online publiziert: 10. November 2016

๑) Springer-Verlag Berlin Heidelberg 2016

Niedersächsische Krebsgesellschaft e.V., Hannover

\title{
8. Tagung der niedersächsischen Krebsselbsthilfegruppenleiter/ innen in Rotenburg
}

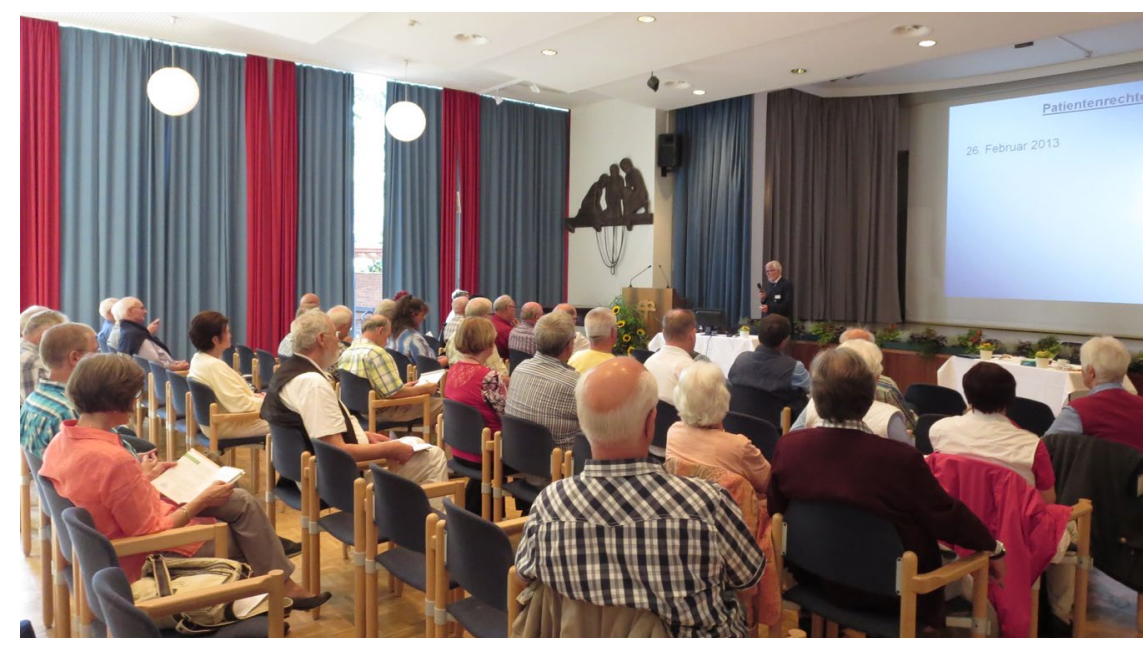

$\Delta$ Blick in den Vortragsraum

ßende angeregte Diskussion zeigte einmal mehr, wie aktuell das Thema für die Gruppenleiter ist und sie bewegt.

In der Mittagspause gab es bei einem guten Essen die Gelegenheit zum ausführlichen Austausch, bevor am Nachmittag der zweite Teil begann: Den ersten Vortrag übernahm der niedergelassene Facharzt für Urologie Jan Franz aus Tostedt zum Thema „Krebs und Sexualität“, den zweiten Vortrag hielt Ludwig Pabst, Hotlineberater Bundes-

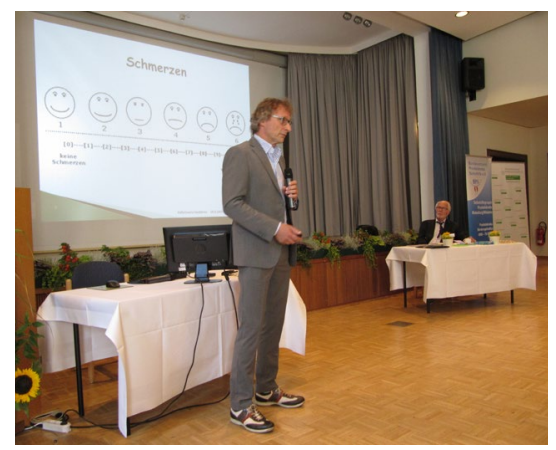

$\Delta$ Dr. Albrecht Werner, Facharzt für Allgemeinmedizin, Palliativmedizin und Balneologie verband Prostatakrebs e.V., zum Thema: „Krebs gezielt erkennen und behandeln“. Er sprach über Hoffnungen in und Erwartungen an die Medizin zur Tumordiagnostik und -therapie aus Patientensicht.

Die Niedersächsische Krebsgesellschaft e. V. veranstaltet diese Tagung einmal jährlich in Zusammenarbeit mit einer KrebsSelbsthilfegruppe aus Niedersachsen. Veranstaltungsorte waren bisher Ganderkesee, Stade, Verden, Lüneburg, Bad Zwischenahn, Cloppenburg und Rotenburg. Das nächste Treffen wird voraussichtlich im September 2017 in Oldenburg stattfinden.

\section{Kontakt}

\section{Dr. Bärbel Burmester \\ Bettina Hallmann \\ Annette Schmidt}

Niedersächsische Krebsgesellschaft e.V.

Königstraße 27

30175 Hannover

Tel.: $0511-3885262$

Fax: $0511-3885343$

E-Mail: service@nds-krebsgesellschaft.de Internet: www.nds-krebsgesellschaft.de

A. Kurtz (Prostatakrebs Selbsthilfegrupp Heidekreis), Bettina Hallmann, Dr. Bärbel Burmester (Nds.KG) 